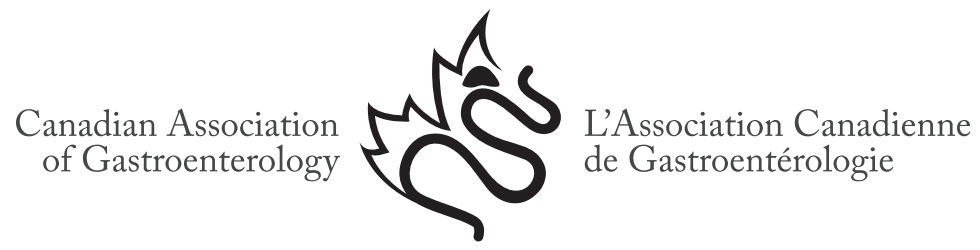

\title{
Canadian Association of Gastroenterology Visiting Research Professorship and Visiting Clinical Professorship
}

\author{
Francois Boudreau VP Research Affairs, Kevin Waschke VP Education Affairs, Canadian Association of Gastroenterology
}

\section{CANADIAN ASSOCIATION OF GASTROENTEROLOGY VISITING RESEARCH PROFESSORSHIP}

The Canadian Association of Gastroenterology (CAG) Visiting Research Professorship is offered annually to a member of the CAG who is a proven teacher and an outstanding researcher. The Visiting Research Professor is asked to visit at least six sites (typically academic centres) across the country during the period of July 1st to June 30th. The CAG supports the cost of the air travel for the Visiting Research Professor while the host sites are responsible for costs of local travel, accommodation, meals, and any honorarium.

\section{Announcing the 2014-2015 CAG Visiting Research Professor -} Dr Paul Moayyedi

Dr Paul Moayyedi qualified in medicine from Bristol University and obtained a PhD and Masters in Public Health from the University of Leeds. He was appointed Professor of Gastroenterology at the University of Birmingham in 2001 and then moved to McMaster University to be the first recipient of the Richard Hunt/AstraZeneca Chair of Gastroenterology in 2004. He became Director of the Division of Gastroenterology at McMaster in 2006 and is Acting Director of the Farncombe Family Digestive Health Research Institute since 2012.

He has conducted a large randomized controlled trial of population $H$ pylori screening and treatment in over 8000 subjects that suggested this is a cost-effective method of reducing gastric cancer mortality. $\mathrm{He}$ is deputy chief investigator of a trial evaluating the role of chemoprevention and surveillance for esophageal adenocarcinoma in Barrett's esophagus and co-principal investigator of another trial evaluating the efficacy of surveillance in Barrett's esophagus. Both have recruited over 2500 patients and are the world's largest Barrett's trials. He is co-principal investigator on a trial evaluating efficacy of fecal transplant therapy in active ulcerative colitis and as a proponent of evidence based medicine. He has conducted a number of systematic reviews on therapies for functional gastrointestinal disorders and inflammatory bowel disease. He has over 270 peer-reviewed publications. His work has been cited over 7700 times with 1194 citations in 2013. His h index is 48 according to ISI Web of Knowledge on March $18,2014$.

$\mathrm{He}$ is joint Editor-in-Chief of the American Journal of Gastroenterology and is also joint Editor-in-Chief of the Upper Gastrointestinal and Pancreatic Diseases Cochrane Review Group.

\begin{abstract}
Thanks to the 2013-2014 CAG Visiting Research Professor Dr Paul Beck, University of Calgary

The CAG would like to express its sincere appreciation to Dr Beck for being the 2013-2014 CAG Visiting Research Professor. Dr Beck was able to visit eight centres during his term (Orford QC, Edmonton, Toronto-twice, Calgary, Vancouver, Kingston, and St John's). This is a remarkable commitment and accomplishment. Our congratulations and thanks to Dr Beck.
\end{abstract}

\section{CAG VISITING CLINICAL PROFESSORSHIP}

The CAG Visiting Clinical Professorship, introduced in 2012, is offered annually to a member of the CAG who is a proven educator and an outstanding clinician with interest in clinical research. The Visiting Clinical Professor will focus his or her visits to that of regional meetings/events vs. academic sites. The recipient of the award is asked to visit at least six centres across Canada during the period of July 1st to June 30th. The CAG supports the cost of the air travel for the Visiting Clinical Professor while the host sites are responsible for expenses related to local travel, accommodation, meals, and any honorarium.

\begin{abstract}
Announcing the 2014-2015 CAG Visiting Clinical Professor Dr Christopher Andrews

Dr Christopher Andrews went to McMaster Medical School, then completed residencies in Vancouver (Internal Medicine) and Calgary (Gastroenterology). This was followed by postgraduate training in gastrointestinal motility and clinical health research at the Mayo Clinic (Rochester). He is a consultant gastroenterologist at Foothills Hospital, Associate Professor in the Division of Gastroenterology at the University of Calgary, and Co-Lead of the Calgary Gut Motility Clinic at the South Health Campus. Dr Andrews' clinical and research interests focus on the diagnosis and management of gut motility disorders, including gastroparesis, intestinal pseudoobstruction, dyspepsia, and irritable bowel syndrome.
\end{abstract}

Thanks to the 2013-2014 CAG Visiting Clinical Professor Dr Robert Enns, University of British Columbia

The CAG would like to express its sincere appreciation to Dr Enns for being the 2013-2014 CAG Visiting Clinical Professor. Dr Enns was able to visit eight centres during his term (Calgary, London, Winnipeg, Quebec City, Toronto, Edmonton, La Paz and the Atlantic Association

The CAG is proud to acknowledge its Benefactor Corporate Sponsors:
AbbVie Corporation
Olympus Canada Inc

Pentax Canada Inc

Janssen Inc

Takeda Canada Inc 
of Gastroenterology Meeting). This is a remarkable commitment and accomplishment. Our congratulations and thanks to Dr Enns.

If you are interested in having Dr Moayyedi or Dr Andrews visit your centre during their term please contact the CAG National Office at general@cag-acg.org.

Nominations for these awards can be made by any member of the CAG. To nominate a candidate please complete the nomination form for these awards found on the CAG website at www.cag-acg.org under
'Recent Listings'. A curriculum vitae must be concurrently forwarded to the CAG National Office, preferably in electronic format. The CAG Research Committee will review the nominations for the Visiting Research Professor and the CAG Education Committee will review the nominations for the Visiting Clinical Professor; each will make recommendations to the CAG Board, who will make the final decision on the recipients. Nominations for these awards must be received by August $31,2014$. 


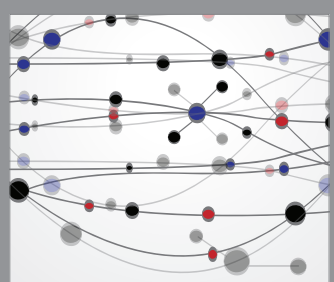

The Scientific World Journal
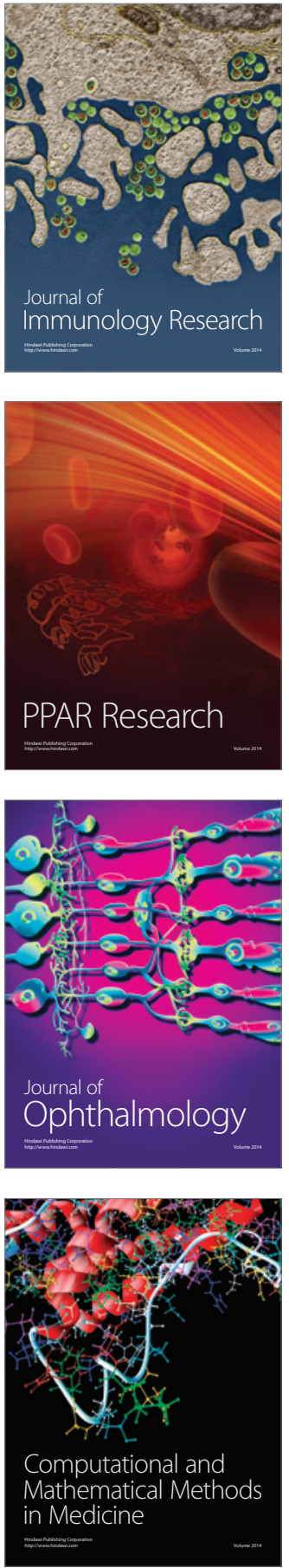

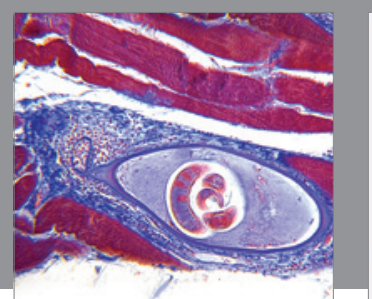

Gastroenterology Research and Practice

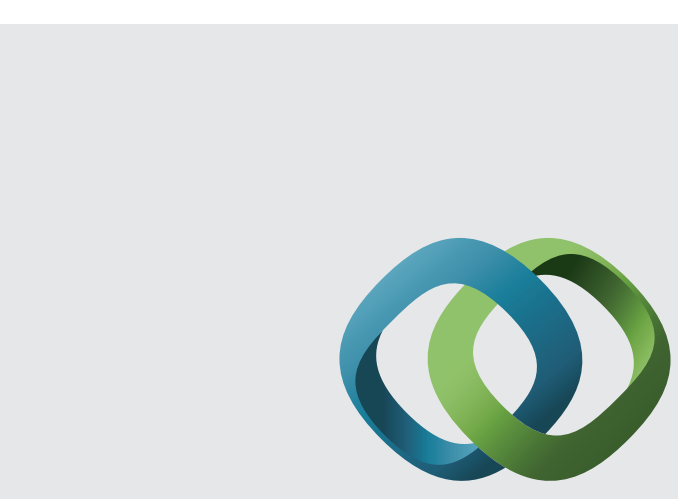

\section{Hindawi}

Submit your manuscripts at

http://www.hindawi.com
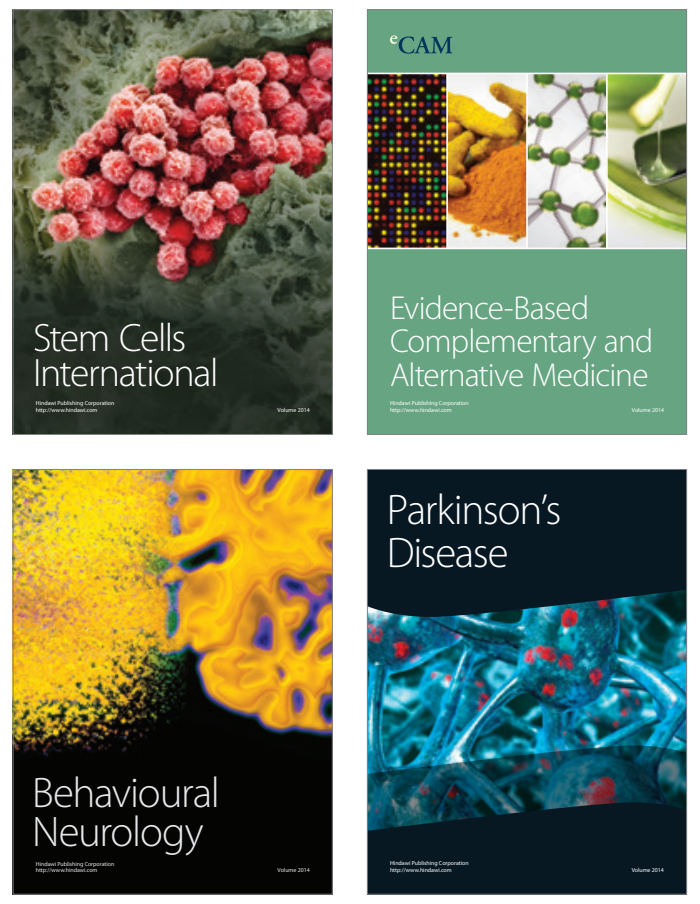
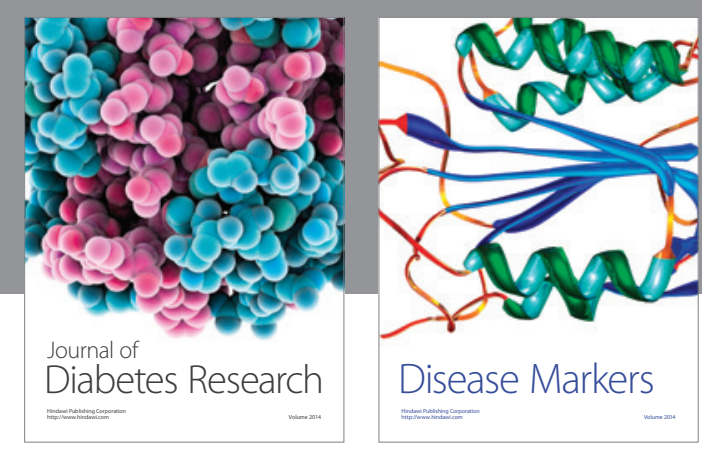

Disease Markers
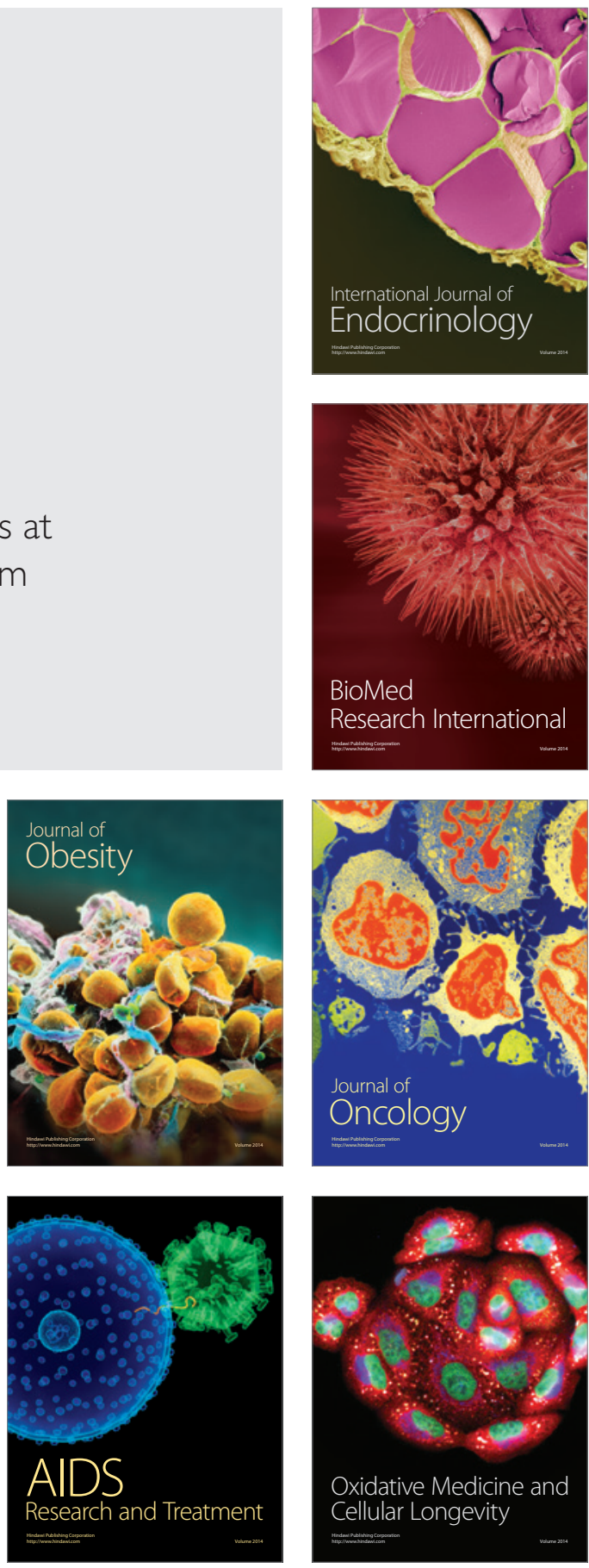